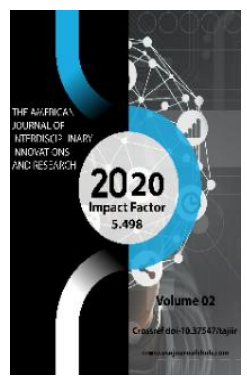

Journal Website: http://usajournalshub.c om/index,php/tajiir

Copyright: Original content from this work may be used under the terms of the creative commons attributes 4.0 licence.

\section{A Preliminary Investigation Of Cassava Starch Potentials As Natural Polymer In Bioplastic Production}

\author{
Ikusedun Mojibayo \\ Federal Institute Of Industrial Research Oshodi , Lagos,Nigeria \\ Akinola O. Samson \\ Federal Institute Of Industrial Research Oshodi , Lagos,Nigeria \\ Obe Yekini Johnson \\ Federal Institute Of Industrial Research Oshodi , Lagos,Nigeria \\ Olagunju O.Joshua \\ Federal Institute Of Industrial Research Oshodi , Lagos,Nigeria \\ Ajani S.A \\ Federal Institute Of Industrial Research Oshodi , Lagos,Nigeria
}

\title{
ABSTRACT
}

Starch consists of two types of molecules namely, amylosse and amylopectin.Amylose, a linear chain polymer constitutes about $20 \%$ of starch. It is more soluble in water, soluble in hot water but does not form gel while amylopectin is a branched chain polymer that constitutes about $80 \%$ of the starch. It is less soluble in water, soluble in hot but forms gel, hence the need for modification. In this study, Cassava starch was modified with distilled water, glycerol and vinegar. The cassava starch, distilled water, vinegar and glycerol were all weighed in required proportions into the beaker. $50 \mathrm{~g}$ of cassava starch was weighed into a beaker, $10 \mathrm{mls}$ of vinegar was added. $20 \mathrm{mls}$ of glycerol was also added. The resulting mixture was thoroughly stirred to form a uniform suspension, the suspension was heated, and it was continuously stirred to avoid coagulation with increasing viscosity until gelatinization was achieved at about $100^{\circ} \mathrm{C}$. The gel was spread on a smooth, hard surface and mechanically pressed to form sheets. The sheets were air dried to cure for $72 \mathrm{hrs}$ to $5 \%$ moisture content. The sheet was subjected to tensile test. Water was used as a solvent to first get the biopolymer (starch) into solution. When the solution was heated, the water helped the starch molecules to become disrupted and disordered (denatured). The reduction of starch hydrogen bonding was achieved in the presence of water. Water diffused into the starch granules and hydrogen bonds breaking down the intermolecular bonds of the starch molecules. Water helped the starch molecules to become disrupted and disordered. When the starch was heated with water, water interacted with hydroxyl 
groups in the starch, thereby reducing hydrogen bonding among the starch molecules. This phenomenon allowed individual molecules to move freely relative to each other, thereby allowing the starch to be melt-processed.

\section{KEYWORDS}

Natural Polymer, Tensile strength, modification, synthetic polymer, bioplastic, cassava starch.

\section{INTRODUCTION}

Plastics are simply chains of like molecules linked together. These chains are called polymers. This is why many plastics begin with "poly," such as polyethylene, polystyrene, and polypropylene. Polymers often are made of carbon and hydrogen and sometimes oxygen, nitrogen, sulfur, chlorine, fluorine, phosphorous, or silicon. The term "plastic" encompasses all these various polymers. Plastics are synthetic or semi synthetic materials made from organic polymers. In other words, while other elements might be present, plastics always include carbon and hydrogen. While plastics may be made from just about any organic polymer, most industrial plastics are petroleum based and are made from petrochemicals.

The world production of plastics is estimated to be more than 10omillions times per year. The need for such quantities of conventional plastics and their dominance over other materials is due to their excellent long life properties. These properties includes: resistance to chemical reactions, especially enzymatic reactions. For example, it can take up to one hundred years to degrade only a few grams of plastic(such as polyethylene) under normal environmental conditions. Degradation at high temperature such as in pyrolysis (burning) tends to cause emission of toxic fumes. Plastic accumulations in the environment thus create tremendous problems for the world, presently and in the future. Environmental problems caused by plastics includes: changes to the carbon dioxide cycle, problems in composting and increased toxic emissions sttimulated by environmental concerns, scientists are now concentrating on ways to develop plastics use more efficiently.

Thermoplastic starch currently represents the most widely used bioplastic, constituting about 50 percent of the bioplastics market. Simple starch bioplastic films and sheets can be made by modifying starch with plasticizers such as glycerol, glycol, and sorbitol and can also be added so that the starch can also be melt processed thermo-plastically. In this work, glycerol ,vinegar (acetic acid) and distilled water were used in starch modification to produce boiplastic sheets.

However, plastics made from petrochemicals do not degrade easily; they can be in the environments for several thousands of years constituting environmental nuisance and challenges. When these plastics are recycled and reused, they still find their way into the environment. Even when they are burnt at landfills, toxic fumes are released into the environment posing health threat to humans 
and there are currently limited spaces for landfill, hence the need for bioplastics production. Bioplastics are plastics derived from renewable biomass sources such as vegetable fats and oils, cassava starch,,food waste etc. In principle they could replace many applications for petroleum-derived plastics, Biodegradable plastics are degradable plastic in which the degradation results from the action of naturally occurring microorganisms such as bacteria, fungi and algae. Bioplastics save more nonrenewable energy than conventional plastics and emit less GHG compared to conventional plastics.

There has been a widespread interest in plastics made from renewable and natural polymers which can degrade naturally and more rapidly than the petroleum-based plastics. Among all biopolymers, starch is

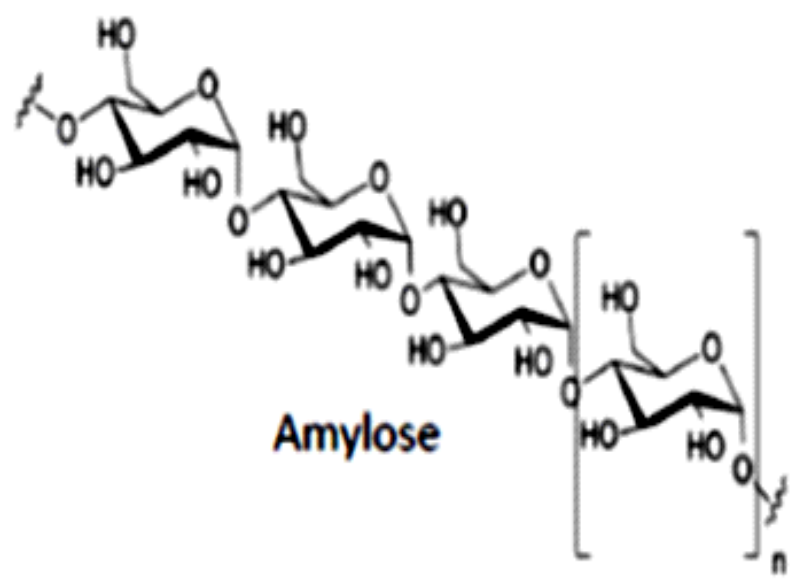

being investigated as a potential material for biodegradable plastics. The main interest in 'biodegradable' plastics is that they break down into simpler components sooner than traditional plastics.

Starch is renewable, readily biodegradable, easily modified and available in bulk in all parts of the world at low cost (estimated global production $>70$ millions tones in 2011, making it a very attractive raw material for "green" plastics production (Jeffry Grotto, 2013). The "Cradle-To-Grave" concept has been designed by the Michigan Biotechnology Institute (1994). As the end use of products from biodegradable plastic is composting, it can serve as a reserve for carbon dioxide and as a means to return nutrients back to the soil (as compost).

Fig 1:Structures of Amylose and Amylpectin of Cassava Starch

From 2003 to the end of 2007, the global average annual growth rate was about 38\% (Shen et al., 2009) considering the promising of bio-based plastics to replace their petrochemical counter parts, the bioplastic industry has a huge market.

According to (Weber 2000), starch-based packaging will continue developing with the support of their niches of traditional non-food 
markets. Later, starch biopolymers should enter the food market, after that resistance to humidity and cost-related prob-lems are solved

The use of starch in the manufacturing of bioplastics began in the 70's (Curvelo et al., 2001). Among its advantages, starch is cheap, abundant and renewable. Besides, it is found in several forms due to the origin of its raw material (Lawter and Fischer, 2000).

To plastify the starch, it is necessary to use a large quantity of plasticizers or destructurating compounds (glycerol,etc.) with hydrophilic properties. Thermoplastic starch currently represents the most widely used bioplastic, constituting about 50 percent of the bioplastics market. Simple starch bioplastic film can be made at home by gelatinizing starch and solution casting. The properties of starch bioplastic is largely influenced by amylose/amylopectin ratio. Generally, high-amylose starch can result in better mechanical properties. However, highamylose starch has less processiblity because of its higher gelatinization temperature and higher melt viscosity.

\section{MATERIALS AND METHODS}

\section{The Study Area}

The study was conducted at the Federal Institute Of Industrial Research Oshodi Lagos Nigeria. The bioplastic production was done at the Pckaging Technology Division of the Institute. Material characterization was done at the department of Polymer Science, Yaba College of Technology, Lagos, Nigeria.

\section{The Modification and Plasticization Process}

Modification of Starch requires the disruption of starch granules and their super molecular
Structures. Starch in its native form cannot be melt-processed because the hydrogen bonds that hold the starch molecules together have to be reduced (disrupted or disordered) to melt-process native starch, the glass temperature (Tg) of pure, dry starch is above the decomposition temperature point, so it does not soften and flow. However, starch can be plasticized by materials (molecules) that are capable of hydrogen bonding with the starch hydroxyl groups, such as water, glycerol or sorbitol. The materials used in this study were cassava starch, distilled water, glycerol and vinegar. The cassava starch, distilled water, vinegar and glycerol were all weighed in required concentrations into the beaker. $50 \mathrm{~g}$ of cassava starch was weighed into a beaker, 10mls of vinegar was added. $20 \mathrm{mls}$ of glycerol was also added. The resulting mixture was thoroughly stirred to form a uniform suspension, the suspension was heated, and it was continuously stirred to avoid coagulation with increasing viscosity until gelatinization was achieved at about $100^{\circ} \mathrm{C}$. The gel was spread on a smooth, hard surface and mechanically pressed to form a sheet. The sheet was air dried to cure for $72 \mathrm{hrs}$ to $10 \%$ moisture content. Tensile strength of the sheet was determined. Water was used as a solvent to first get the biopolymer (starch) into solution. When the solution was heated, the water helped the starch molecules to become disrupted and disordered (denatured). The reduction of starch hydrogen bonding was achieved in the presence of water. Water diffused into the starch granules and hydrogen bonds breaking down the intermolecular bonds of the starch molecules. Water helped the starch molecules to become disrupted and disordered. When the starch was heated with water, water interacted with hydroxyl groups in the starch, thereby reducing hydrogen bonding among 
the starch molecules. This phenomenon allowed individual molecules to move freely relative to each other, thereby allowing the starch to be melt-processed.

Vinegar contains acetic acid which forms hydrogen ions and acetate ions, the vinegar's free Hydrogen ions interacted with the starch molecules which made them more easily disrupted and disordered. Vinegar helped the starch to dissolve better, so vinegar was used to increase starch solubility.

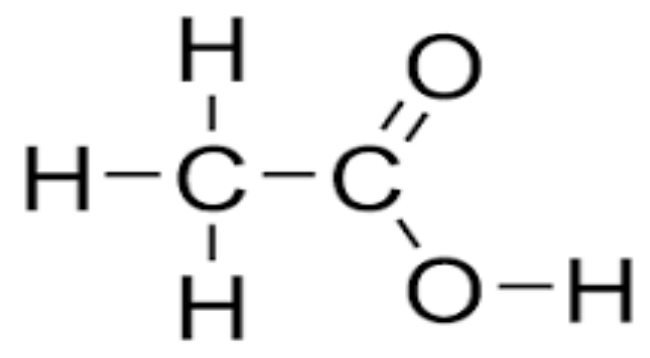

Fig 2: Structure of Vinegar

Glycerol (Propan-1, 2, 3-triol) $\rightarrow$ It is a hygroscopic liquid with a high viscosity. It has three hydroxyl groups which makes it soluble in water. It increased the flexibility and workability of the plastics. With the hydroxyl groups, it has the affinity to form hydrogen bonds with water molecules. Glycerol made a very useful plasticizer in the formulation. Glycerol made the polymer chain molecules to bend and slide past each other more easily, which added to the flexibility and durability of the plastic.

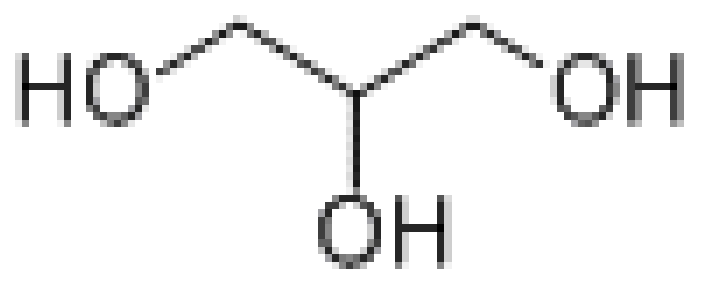

Fig 3: Structure of Glycerol 


\section{Methodology flow chart}

Collection of Materials

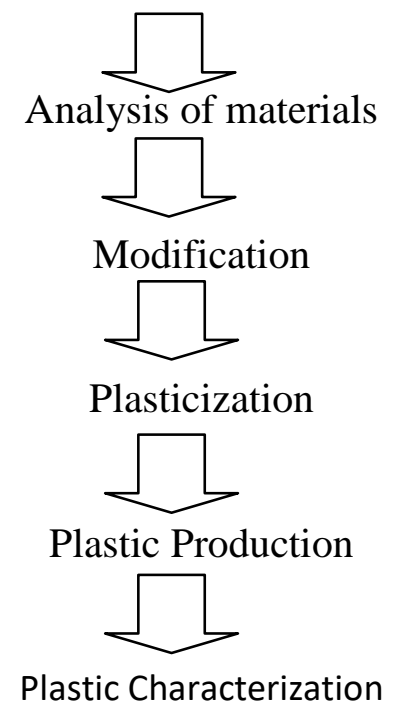

Table 1: Specimen Geometry of Analyzed Bioplastic Sample

\begin{tabular}{|l|l|c|c|}
\hline S/N & PARAMETERS & VALUES & UNIT \\
\hline 1 & Thickness & 1.00 & Mm \\
\hline 2 & Length & 80.00 & $\mathrm{Mm}$ \\
\hline 3 & Width & 30.00 & $\mathrm{Mm}$ \\
\hline
\end{tabular}


Table 2: Tensile Properties of Analyzed Bioplastic Sample

\begin{tabular}{|l|l|l|l|}
\hline S/N & SPECIFICATION & VALUE & UNIT \\
\hline 1 & Yield load & 1.10 & $\mathrm{Kgf}$ \\
\hline 2 & Yield Elongation & 0.60 & $\mathrm{Mm}$ \\
\hline 3 & Tensile Strength at Yield Load & 3.67 & $\mathrm{Kg} / \mathrm{cm}^{2}$ \\
\hline 4 & Breaking Load & 3.70 & $\mathrm{Kgf}$ \\
\hline 5 & Elongation at Break Load & 4.10 & $\mathrm{Mm}$ \\
\hline 6 & Tensile Strength at Breaking Load & 12.33 & $\mathrm{Kg} / \mathrm{cm}^{2}$ \\
\hline 7 & Tenacity at Breaking Load & 0.00 & $\mathrm{Gms} /$ Denier \\
\hline 8 & Elongation \% at Break & 5.13 & $\%$ \\
\hline 9 & Maximum Load & 5.20 & $\mathrm{Kgf}$ \\
\hline 10 & Elongation at maximum Load & 2.80 & $\mathrm{Mm}$ \\
\hline 11 & Tensile Strength at Maximum Load & 17.33 & $\mathrm{Kg} / \mathrm{cm}^{2}$ \\
\hline 12 & Tenacity at Maximum Load & 0.00 & $\mathrm{Gm} /$ Denier \\
\hline 13 & Elongation \% at maximum Load & 3.50 & $\%$ \\
\hline 14 & Modulus Elasticity & 488.89 & \\
\hline 15 & $0.1 \%$ Offset Yield Strength & 0.00 & \\
\hline
\end{tabular}




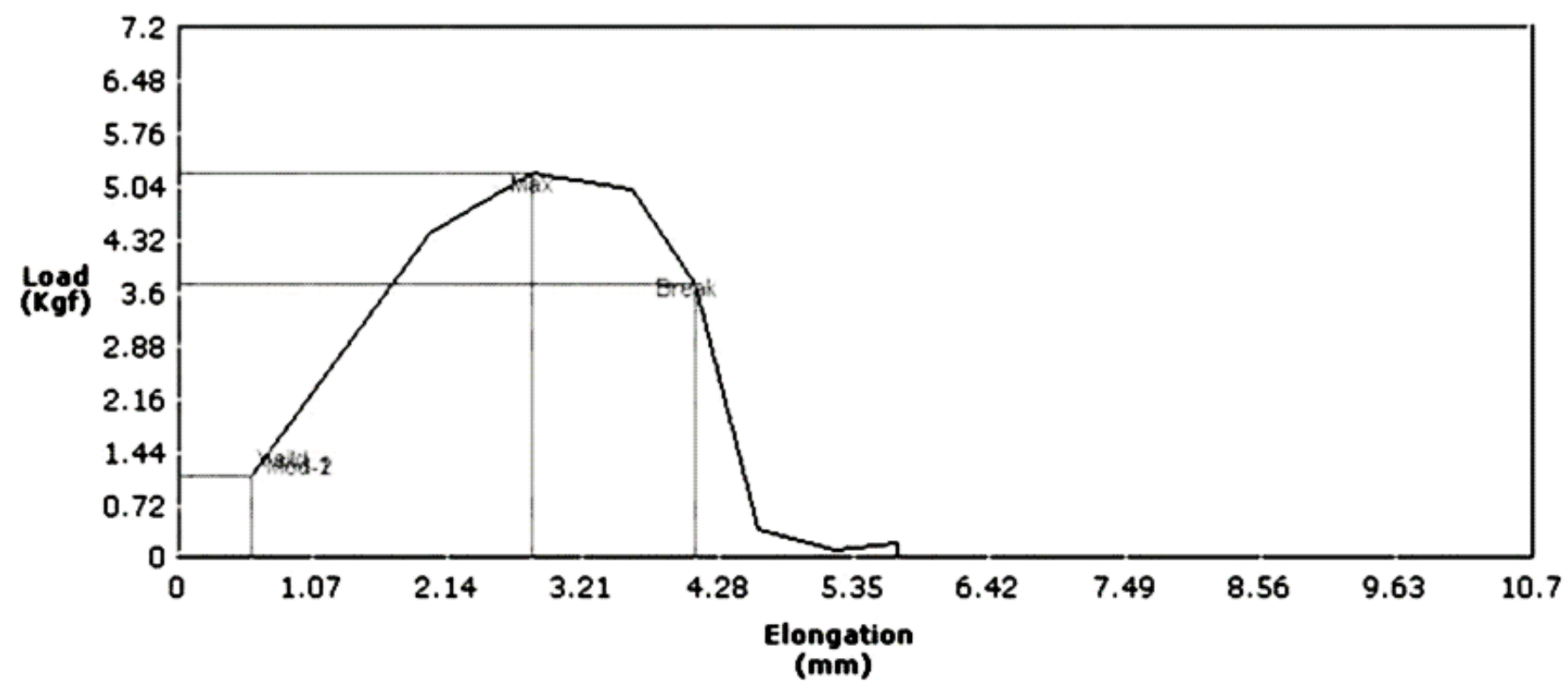

Fig 4: Load -Elongation Graph

\section{RESULTS AND DISCUSSION}

Tensile strength is measured by the maximum stress that a material can withstand while been stretched or pulled before breaking. It is an intensive property; therefore, its value does not depend on the size of the test specimen. However, It is dependent on other factors, such preparation of the specimen, the presence or otherwise of surface defect, and the temperature of test environment and the materials. From table 1 above, the specimen geometry shows that the bioplastic sample analyzed has $1.00 \mathrm{~mm} 80.00 \mathrm{~mm}$ and 30.00 for thickness, length and width respectively. Results from table 2 and the load-elongation graph show that the sample was able to withstand the maximum load of $5.20 \mathrm{kgf}$ with $2.80 \mathrm{~mm}$ elongation at maximum load and tensile strength of $17.33 \mathrm{~kg} / \mathrm{cm} 2$ at maximum load. The values above are good for a $100 \%$ bioplastic sheet. The results of the study show that cassava starch as a natural polymer has potentials in bioplastic production.

\section{CONCLUSION}

The investigation of cassava starch as a natural polymer in bioplastic production, show that starch as a natural polymer can replace petroleum based polymers mostly used in plastic production The bioplastic produced from 100 percent cassava starch was found to possess good tensile properties acceptable for bioplastic. This is as a result of proper starch modification with water glycerol and vinegar. The result also show that the bioplastic sheet produced exhibited plastic behavior 


\section{REFERENCES}

1. Avant, Sandra (April 2017). "Better Paper, Plastics With Starch". USDA. Archived from the original on 2018-12-14. Retrieved 2018-12-14.

2. Dufresne, A.; Cavaille, J-Y.; Vignon, R. Mechanical behavior of sheets pre $\neg$ pared from sugar beet cellulose microfibrils. Journal of Applied Polymer Science, New York, v.64, p.1185-1194, 1997.

3. Fringant, C; Rinaudo. M.; Gontard, N.; Guilbert. S. E Derrad.I1. H. A biodegradable starch based coating to waterproof hydrophilie materials. Starch/ Starke, Weinhein, v.50, n.7, p.292-296, 1998.

4. Haugaard, V.K; Udsen, A.M.; Mortensen, G; Hoegh, L.; Petersen. K. E Monahan, F. Potential of Food Applications of Biobased Materials. An EU-Concerted Action Project. Starch/Stdrke, Weinhein, v.53, p. 189-200, 2001.

5. Kaplan, D.L. (ed.) Biopolymers from renewable resources. Berlin: SpringerVerlag. 1998. p. 1-29.

6. Khalid, Saud; Yu, Long; Meng, Linghan; Liu, Hongsheng; Ali, Amjad; Chen, Ling (2017). "Poly(lactic acid)/starch composites: Effect of microstructure and morphology of starch granules on performance". Journal of Applied Polymer Science. 134 (46): n/a. doi:10.1002/app.45504.

7. Liu, Hongsheng; Xie, Fengwei; Yu, Long; Chen, Ling; Li, Lin (2009-12-01). "Thermal processing of starch-based polymers". Progress in Polymer Science. 34 (12): 1348-1368.

doi:10.1016/j.progpolymsci.2009.07.001. ISSN $0079-6700$.

8. Li, Ming; Liu, Peng; Zou, Wei; Yu, Long; Xie, Fengwei; Pu, Huayin; Liu, Hongshen; Chen, Ling (2011-09-01). "Extrusion processing and characterization of edible starch films with different amylose contents". Journal of Food Engineering. 106 (1): 95-101. doi:10.1016/j.jfoodeng.2011.04.021. ISSN 0260-8774.

9. M.P. Cereda, C.M Henrique, M.A. Oliveira, M.V. Ferraz, and N.V Vicentini, Characterization of edible films of cassava starch by electron

10. Sherman, Lilli Manolis (1 July 2008). "Enhancing biopolymers: additives are needed for toughness, heat resistance \& processability". Plastics Technology. Archived from the original on 17 April 2016.

11. Song, J. H.; Murphy, R. J.; Narayan, R.; Davies, G. B. H. (2009-07-27). "Biodegradable and compostable alternatives to conventional plastics". Philosophical Transactions of the Royal Society B: Biological Sciences. 364 (1526): 2127-2139. doi:10.1098/rstb.2008.0289. ISSN 0962-8436. PMC 2873018. PMID 19528060. 